\title{
Diagnosis of bovine foot and mouth disease virus by real-time polymerase chain reaction and nucleotide sequencing from outbreak herd samples in I lesha Baruba, Kwara state, Nigeria
}

\author{
Olatunde Hamza Olabode ${ }^{1,2}$, Haruna Makajuola Kazeem² and Mashood Abiola Raji²
}

\author{
1. Department of Veterinary Microbiology, Faculty of Veterinary Medicine, University of Abuja, Abuja, Nigeria; \\ 2. Department of Veterinary Microbiology, Faculty of Veterinary Medicine, Ahmadu Bello University, Zaria, Nigeria. \\ Corresponding author: Olatunde Hamza Olabode, e-mail: olabodeok@yahoo.com, \\ HMK: haruna_kazeem@yahoo.com, MAR: rajmash2002@gmail.com \\ Received: 23-05-2014, Revised: 06-09-2014, Accepted: 10-09-2014, Published online: 27-10-2014
}

doi: 10.14202/vetworld.2014.868-875. How to cite this article: Olabode OH, Kazeem HM, Raji MA (2014) Diagnosis of bovine foot and mouth disease virus by real-time polymerase chain reaction and nucleotide sequencing from outbreak herd samples in Ilesha Baruba, Kwara state, Nigeria, Veterinary World 7(10): 868-875.

\begin{abstract}
Aim: Molecular diagnosis of bovine foot and mouth disease virus (FMDV) from outbreak herd in Bukaru-Rontuwa, Sinawu/ Tumbunya ward of Ilesha Baruba, in Kwara state-Nigeria was conducted to establish the associated serotypes and disease control plan.

Materials and Methods: Purposive study was conducted in cattle outbreak herds during the dry season of January-March, 2011. Random sampling of blood and observed epithelial tissues was collected, stored in accordance with standard methods and subjected to RNA extraction and real-time reverse transcription polymerase chain reaction (rRT-PCR). Positive samples for FMDV were further subjected to reverse transcription polymerase chain reaction (RT-PCR), nucleotide sequencing using sequence primers of serotypes O, A, SAT 1-3 and gel electrophoresis. Obtained data were interpreted based on NCBI BLASTN program.

Results: Foot and mouth disease (FMD)-RNA extract was not found in all the blood tested with beta-actin range of $\mathrm{Ct}=30-34$. rRT-PCR assay showed two positive samples with Ct values of 18.79 and 15.28. Gel electrophoresis identified sequenced PCR amplicons as serotype A and SAT 2 respectively. Direct product sequencing confirmed SAT 2 serotype was closely related to SAT 2 isolate LIB/7/2003. Cloned RT-PCR product in pGEM-T easy vector confirmed serotype A as closely related to sequence of A/NIG/21/2009, though multiple NIG/2009 sequences were also identified as closely related. Both isolates showed marked genetic homogeneity with $>93 \%$ genetic identity in the VP1 region which confirmed heterogeneity and antigenic variation nature of FMDV.

Conclusion: Quasi species and subtypes of FMD serotypes A and SAT 2 similar to A/NIG/21/2009 and SAT 2/LIB/7/2003 respectively caused the reported FMD outbreaks in Fulani livestock herds investigated. A combined real-time and optimized RT-PCR protocols that would facilitate effective and timely FMD outbreak control plan based on identified serotypes is thus suggested.
\end{abstract}

Keywords: foot and mouth disease virus, Ilesha Baruba, Kwara State, molecular, outbreaks, phylogenetic.

\section{I ntroduction}

Foot and mouth disease (FMD), is a highly contagious viral disease of both domestic and wild cloven hoofed animals, caused by a single-stranded picona-virus, positive RNA genome [1] characterized by high morbidity and exclusion of affected countries from International Animal Trade participation [2]. The FMD virus (FMDV) consists of approximately 8,500 bases that encode a large polyprotein that cleaves into structural proteins and nonstructural proteins with four structural proteins forming an icosahedral capsid. The structural protein region is highly variable while nonstructural protein (3D pol RNA polymerase) gene is a highly conserved region amongst different seroand subtypes of FMDV [3]. Seven distinct serotypes exist, namely Type A, O, C (European types), South African types (SAT1, SAT 2, SAT 3) and Asiatic type

Copyright: The authors. This article is an open access article licensed under the terms of the Creative Commons Attributin License (http:// creative commons.org/licenses/by/2.0) which permits unrestricted use, distribution and reproduction in any medium, provided the work is properly cited. with characteristic antigenic variation capacity [4]. Cumulative incidence of FMD serotypes showed six of the seven serotypes (O, A, C, SAT-1, SAT-2, SAT-3) occurred in Africa [5] confounding disease control and aggravating economic losses [6] especially in Nigeria [7] due to increasing number of outbreaks following vicious cycle of recurrent serotypes A, O, SAT 1 and SAT 2 circulation in the last 54 years (1955-2009)[8].

Early detection is essential for effective control which requires rapid and sensitive method of viral serotype diagnosis responsible for an outbreak and selection of an appropriate emergency vaccine [2] which is currently unavailable in Nigeria [8]. Nucleic acid recognition tests, such as the reverse transcription polymerase chain reaction (RT-PCR) are being used increasingly as rapid and sensitive diagnostic method [9]. However, fast and reliable automated real-time-PCR provides an alternative procedure against the manual RT-PCR [10]. These assays characteristically possess high analytical sensitivity, high 
specificity and the ability to detect diverse FMDV strains (pan-reactivity) as an additional requirement over any routine FMD diagnostic assay [11]. In Nigeria, much attention is not given to FMD control and as a fall-out beef export contributes insignificantly to economic development as reflected by global distribution [2] due to trade exclusion from lucrative world markets [12]. Despite annual FMD burden, serotyping and molecular studies are inadequate. Hence, occurrence and distribution pattern of the known serotypes remains unexploited and poorly understood. Therefore, establishing and quantifying spatial distribution of serotypes will contribute to our understanding of FMD epidemiology, particularly for researchers, donors (development partners) and policy makers who make decisions affecting animal movements and financial allocation for disease control.

Hence, this study seeks to identify the serotypes associated with FMD outbreaks through detection, amplification and sequencing of FMD genes from outbreak epithelial tissues.

\section{Materials and Methods}

\section{Ethical approval}

The research procedure was approved by the faculty of veterinary medicine, staff and postgraduates seminar committee in Ahmadu Bello University Zaria, Kaduna State of Nigeria. The samples were collected, stored and analyzed using standard protocols as recommended by FMD World Reference Laboratory, Pirbright, UK.

\section{Study area}

Ilesha Baruba is a major town and district in Baruten Local Government Area of Kwara state where the Cattle International market is located, for trade activities of cattle from Mali, Togo, Benin, Cote d voire/Burkina Faso and Senegal [13]. Baruten Local Government Area is uniquely located in North western part of Kwara state in Nigeria and shares boundaries in the West with Benin Republic, in the South with Irepo Local Government Area of Oyo State, in the North with Babana district in Borgu LGA of Niger State and in the East by Kaiama LGA of Kwara State [14]. The proximity of cattle trek route from Paraku (Benin Republic border) to the FMD outbreak Fulani settlement in Bukaru-Rontuwa, Sinawu/Tumbunya ward as well as the high livestock concentration and marketing activities in Ilesha Baruba district premised the choice of this study area.

\section{Study design}

This purposive study involved two cattle herds in three FMD outbreaks within Bukaru-Rontuwa, Sinawu/Tumbunya ward of Ilesha Baruba district, Baruten Local Government Area of Kwara state between January and March, 2011. The herds were sampled based on owner compliance and presence of clinical disease during investigation. For each herd, infected cattle were randomly selected for examination and whole blood as well as epithelial samples was collected from those with pathognomonic FMD lesions. A total of 18 blood and three epithelial samples were collected from three herds for analysis.

\section{Sample collection}

Epithelial samples was collected from ruptured vesicle on the tongue, buccal mucosa or feet and placed in transport medium composed of equal amounts of glycerol $(50 \% \mathrm{v} / \mathrm{v})$ and $0.04 \mathrm{M}$ phosphate buffer, $\mathrm{pH}$ 7.2-7.6, with added antibiotics (penicillin [1000 international units (IU)], neomycin sulphate [100 IU], polymyxin B sulphate [50 IU], mycostatin [100 IU]). Samples was kept on ice and transported to the laboratory for storage at $4^{\circ} \mathrm{C}$ and $-20^{\circ} \mathrm{C}$ until use as recommended [15].

Whole blood was also collected using $10 \mathrm{ml}$ syringe and $18 \mathrm{G} 1^{1 / 2}$ needle through the Jugular vein of well restrained FMD infected cattle into $5 \mathrm{ml}$ ethylene diamine, tetra-acetic acid (EDTA) containing plastic bottles $\left(\right.$ maxiCom $\left.{ }^{\mathrm{R}}\right)$. These samples were packed on ice and transported to the laboratory for refrigeration at $4^{\circ} \mathrm{C}$ until used for RNA extraction.

\section{Sample processing}

Samples were centrifuged to pelletize tissues for homogenization and supernatant was kept in case the tissue samples were insufficient. Tissue samples were homogenized by high-speed tissue vortexing with addition of glass beads; the obtained suspensions were stored for RNA extraction, and subsequently real-time PCR, RT-PCR and sequencing. These protocols were conducted in accordance with World Reference Laboratories (WRL), Pirbright, UK and Office International des Epizooties (open information extraction [OIE], Paris, France) guidelines [15] at the Foot-Mouth-Disease Laboratory, National Centre for Animal Diseases, Manitoba-Canada.

\section{RNA extraction using RNeasy spin-columns method}

Total RNA template was extracted following OIE/WRL Pirbright protocol as described [16], using RNeasy mini kit (Qaigen, Germany) in accordance with manufacturer's recommendation. Each tissue sample suspension was lysed using an equal volume of $460 \mu \mathrm{l}$ lysis buffer, and 70\% alcohol was added and mixture loaded on RNeasy spin column and washed twice. The RNA was eluted with $50 \mu \mathrm{l}$ DEPC- $\mathrm{dH}_{2} \mathrm{O}$ into clean collection tube and spin in a micro centrifuge for $60 \mathrm{~s}$ at 10, $000 \mathrm{rpm}$. Extracted RNA was kept on ice for immediate use or stored at $-20^{\circ} \mathrm{C}$ until use for real-time reverse transcription polymerase chain reaction (rRT-PCR) and RT-PCR.

\section{Real-time PCR}

Reversed transcription of FMDV RNA and PCR amplification of reversed transcribed RNA was conducted using automated real-time PCR as prescribed by OIE, (2012) and regarded as smart cycler II and beta-actin rRT-PCR as described [17]. This method amplified a conserved segment of the FMDV RNA 
polymerase gene (3D). The following primers were used 5'-ACTGGGTTTTAYAAACCTGTGATG-3' and $5^{\prime}-$ TCAACTTCTCCKGATGGTCCCA-3' (FMDV 1186F sequence and FMDV $1237 \mathrm{R}$ sequence respectively) alongside with the probe 5'-FAMTCCTTTGCACGCCGTGGGAC-TAMRA-3' (labeled with 6-carboxyfluorescein at the 5' end, and the quencher tetramethyl rhodamine at the 3' end). Reactions were performed using, $2 \mu \mathrm{l}$ and $5 \mu \mathrm{l}$ of the RNA sample template added onto $23 \mu$ FMD master mix and $20 \mu$ l beta-actin master mix respectively in reaction tubes (Cepheid, Sunnyvale, CA) and inserted into the small cycler machine slots. TE buffer (Tris EDTA was used as a negative control. The real-time PCR reactions were carried out in a smart cycler II thermocycler (Cepheid Inc.). The one-step real-time PCR amplification started with reverse transcription (RT) at $50^{\circ} \mathrm{C}$ for $30 \mathrm{~min}$; followed by activation at $95^{\circ} \mathrm{C}$ for $15 \mathrm{~min}$; followed by 50 cycles of $95^{\circ} \mathrm{C}$ for $1 \mathrm{~s}$ and $60^{\circ} \mathrm{C}$ for $1 \mathrm{~min}$. One positive and 1 negative control were included in each reaction. The automated smart cycler machine connected to a computer loaded with "smart cycler" software displaced the cycling profile as FAM (FMDV detection) and TET (surfactant protein $\mathrm{C}$ or beta-actin detection) graphs.

Ct values <35.99 were considered positive. Amplication with Ct value between 35.99 and 40.00 and or low curve to the threshold sample was considered suspicious or doubtful while, Ct value $>40$ was considered negative. Acceptable Ct range for beta-actin positive was between 12 and 35.99.

\section{RT of virus RNA}

Oligonucleotide primers for RT-reaction and subsequent PCR amplification were used as previously published [16]. Briefly, the mixture $(11 \mu \mathrm{l})$ of $10 \mathrm{mM}$ dNTPs, $\times 5$ RT buffer (with dithiothreitol), Moloney murine leukemia virus (200 U/ $\mu \mathrm{l}) \mathrm{RNasin}(3.3 \mathrm{U} / \mu \mathrm{l})$, DEPC- $\mathrm{H}_{2} \mathrm{O}$, and primers $(25 \mathrm{pmol} / \mu \mathrm{l})$ was added to $14 \mu \mathrm{l}$ of each RNA template to make up a total volume of $25 \mu \mathrm{l}$ in sterile $0.75 \mathrm{ml}$ eppendorf tubes. Then spin briefly in a microfuge before heating at $42^{\circ} \mathrm{C}$ for $60 \mathrm{~min}$ and at $94^{\circ} \mathrm{C}$ for $10 \mathrm{~min}$ in a thermocycler. "RT product" tubes were labeled and stored at $-20^{\circ} \mathrm{C}$.

\section{PCR for FMDV detection}

PCR amplification of reverse transcribed RNA reaction was optimized as previously described [16] for PCR using degenerative primers for O-A-C (Alfonso primers produced by North American Conservation Area Database [NCAD]), Canada [17] and SAT 1-3 serotypes primers based on published oligonucleotides [16]. Briefly, in a sterile $0.75 \mathrm{ml}$ tubes, $25 \mathrm{mM}$ $\mathrm{MgCl}_{2}$ with concentrations $1.5 \mathrm{mM}, 10 \mathrm{mM}$ dNTPs $(200 \mu \mathrm{M}), \times 10$ buffer, primers $(0.5 \mathrm{pmol} / \mu \mathrm{l})$, Taq DNA polymerase $(5 \mathrm{U} / \mu \mathrm{l}) 2.5 \mathrm{U}$, RT product and DEPC- $\mathrm{H}_{2} \mathrm{O}$ was added to make a final volume of $50 \mu \mathrm{l}$. Then $20 \mu \mathrm{l}$ mineral oil was added to the top the mixture before it was spin. This mixture was heated in thermocycler at $94^{\circ} \mathrm{C}, 4 \mathrm{~min}, 1$ cycle: $94^{\circ} \mathrm{C}, 60 \mathrm{~s}, 55^{\circ} \mathrm{C}, 60 \mathrm{~s}, 72^{\circ} \mathrm{C}$,
$90 \mathrm{~s}$ in 30 cycles and lastly, $72^{\circ} \mathrm{C}, 5$ min, 1 cycle. The PCR product was stored until used.

\section{Sequencing of $\mathrm{PCR}$ products}

The PCR amplicons was directly sequenced for strain characterization of capsid region VP1/1D gene as described [16] using sequencing primers designed by the Pirbright Laboratory for SAT 1-3 serotypes and Alfonso Primers (NCAD, Canada) for serotypes O, A, $\mathrm{C}$ and promega F-Mol ${ }^{\circledR}$ kit based on manufacturer's instruction. Briefly, purification of PCR Products was done using Promega Wizard Preps ${ }^{\mathrm{TM}}$ and cloned into pGEM-T easy vector and stored $-20^{\circ} \mathrm{C}$ in $0.75 \mathrm{ml}$ eppendorf tubes. End-labeling of oligonucleotide primers was then carried out using T4 polynucleotide kinase. Isolates were labeled, and $1 \mu \mathrm{l}$ of the appropriate $\mathrm{dd} / \mathrm{dNTPs}$ was added, spin briefly in a microfuge and stored at $4^{\circ} \mathrm{C}$. In a separate tube, template DNA, $\times 5$ sequencing buffer, adenosine triphosphate labeled primers, sequencing grade Taq polymerase $(5 \mathrm{U} / \mu \mathrm{l})$ and DEPC- $\mathrm{H}_{2} \mathrm{O}$ were added for each reaction set, mixed and spin, then mineral oil was addition to top reaction mixture. The mixture was placed in a preheater thermal cycler at $94^{\circ} \mathrm{C}$, and $4 \mu \mathrm{l}$ stop solution was added and spin down. The reaction mixture was then heated at $80-90^{\circ} \mathrm{C}$ for $2-5$ min before gel electrophoresis. Sequenced recombinant plasmids data were compared to GenBank data base.

\section{Gel electrophoresis of cycle sequencing products}

Gel electrophoresis of cycle sequencing products was conducted as described [16] using serotype A-O-C (Alfonso NCAD, Canada) and SAT 1-3 (Pirbright, UK) sequencing primers. Auto-radiograph developed was labeled with the name of each sample.

\section{Sequence analysis}

Sequence analysis was conducted using TREEVIEW software as described [18]. The dendogram tree-view was produced from sequence obtained using basic local alignment search tool (BLAST) pairwise alignments and fast minimum evolution based on BLASTN program from NCBI. The BLAST computed a pairwise alignment between a query and the database sequences searched. In this sequence tree presentation was an implicit alignment between the databases sequences constructed, based upon the alignment of database sequences to the query.

\section{Result}

RNA extraction protocol conducted showed no FMDV extract in all the blood tested. The beta-actin result for blood ranged from $\mathrm{Ct}=30-34$. The realtime-PCR assay which targeted the FMDV 3D gene showed two positive samples with Ct values 18.79 and 15.28. Positive and control samples produced from sequenced PCR fragments with $730 \mathrm{bp}$ and 715 bp respectively (Figures-1 and 2) indicated bands of serotype A and SAT 2.

The nucleotide sequencing of PCR amplicons determined and compared for each sample with the 


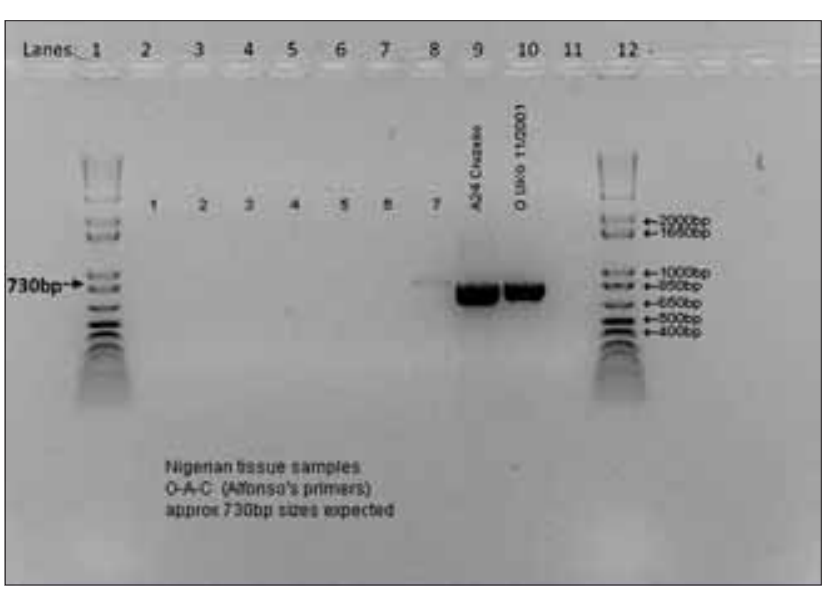

Figure-1: Agarose gel showing amplicons of reverse transcription polymerase chain reaction for foot and mouth disease (FMD) using O-A-C primers (730 bp). A $730 \mathrm{bp}$ polymerase chain reaction product resulting from amplification of FMD virus RNA extracted from epithelial tissues. Lane 1: DNA size marker, ladder 100: negative sample, Lane 2-7: Positive sample, Lane 8: Positive control of serotype A, Lane 9: Positive control of serotype O, Lane 10: Negative control, Lane 11 and Lane 12: DNA size marker, ladder 100.

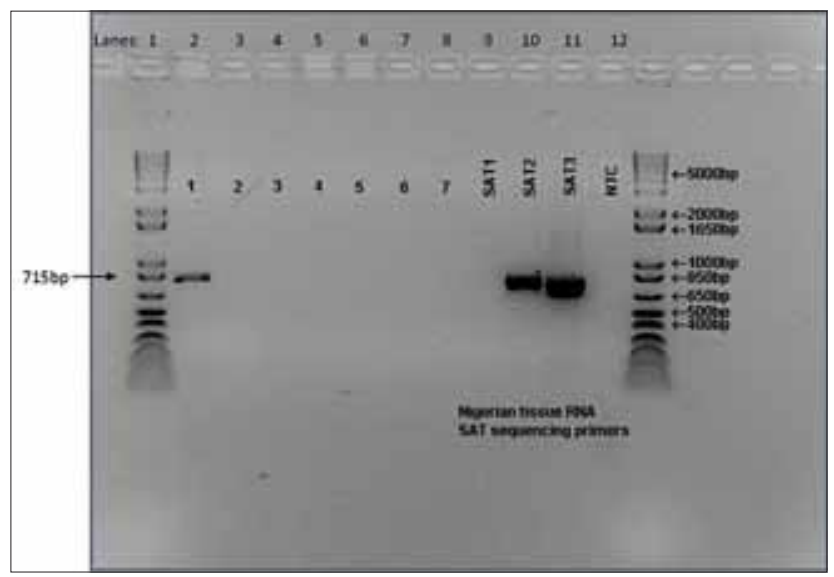

Figure-2: Agarose gel showing amplicons of reverse transcription polymerase chain reaction for foot and mouth disease (FMD) using SAT primers (730 bp, $715 \mathrm{bp}$ and 718 bp for SAT $1,2,3$ ). A 715 bp polymerase chain reaction product resulting from amplification of FMD virus RNA extracted from epithelial tissues Lane 1: DNA size marker, ladder 100, Lane 2: Positive sample, Lane 3-8: Negative samples, Lane 9: Positive control of SAT1, Lane 10: Positive control of SAT2, Lane 11: Positive control of SAT3, Lane 12: Negative control and Lane 13: DNA size marker, ladder 100.

Gene Bank data base revealed test specificity and confirmed identified serotypes as closely related to A/ NIG/21/2009, though multiple NIG/2009 sequences were also identified for serotype A while the closest related sequence in the genbank was SAT 2/ LIB/7/2003 for SAT 2 serotype as shown in the subset tree-view dendograms in Figures-3 and 4.

\section{Discussion}

Investigating molecular epidemiology and distribution of FMD serotypes in outbreak herds is essential for establishing disease control measures by the provision of basic information. Over the past decades, un-robust FMD studies have been performed with different molecular typing methods and limited sequencing efforts. In this study, FMD serotypes and sequences were investigated in a rapid, unambiguously and cost effective approach using automated real-time PCR and direct sequencing post optimized RT-PCR using sequencing primers for region VP1/1D gene as previously described [16]. Out of the three epithelial tissues sampled in this study, two were positive by rRT-PCR for FMDV strains (Table-1) and identified as serotype A and SAT 2 (Figures-1 and 2) respectively from sequenced PCR fragments of 730 and $715 \mathrm{bp}$. This finding is similar to previous reports of un-sequenced serotype A and SAT 2 associated outbreaks in Oyo state [19].

The repeated outbreak within 2 months in the same herd by serotype A and SAT 2 demonstrates the low cross reactivity between serotypes of FMDV [3] as immunity to one serotype is not conferred on another serotype. The cattle trek route proximal to the outbreak herds in this study area (Bukaru-Rontua) may also have facilitated the re-infection with SAT 2 serotype due to environmental viral contamination during cattle transit.

In this study, obtained sequences of $\mathrm{A} /$ NIG/1/2011 and SAT 2/NIG/3/2011 were closely related to isolates of $\mathrm{A} / \mathrm{NIG} / 21 / 2009$ and SAT 2/ LIB/7/2003 as both isolates showed marked genetic homogeneity with $>93 \%$ genetic identity in the VP1 region although multiple NIG/2009 sequences were also identified as closely related for serotype A. This observed multiple sequences are in line with previous documented heterogeneity amongst serotypes [20] associated with antigenic variation and quasi-species characteristics of FMDV genome [3] causing diverse outbreaks in aberration to parental serotypes.

Although, identified serotype A was also remotely related to the cluster of Type A isolate SUD/3/2006 VP1 (1D) gene while the branded SAT 2 was also related to the cluster of SAT 2 isolate NAM/1/92 VP1 gene as shown as subsets in Figures-3 and 4 respectively. The marked genetic homogeneity of SAT 2 involved in this outbreak with sequence of SAT 2/LIB/7/2003 could be associated with viscous cycle of outbreak re-occurrence and genetic recombination [3] facilitated by extensive nomadic flock movement across the Sudano-Sahelian region into sub-Saharan Africa as majority of livestock trade enter into Nigeria, driven by protein demand for the growing population [21].

Occurrence of SAT 2 in this outbreaks further confirms serotype endemicity in sub Saharan Africa [22] as SAT 2 was most frequently associated with FMD outbreaks in southern and West Africa livestock evident in continuous cattle migration from in and out of representative countries such as Senegal, Liberia, Ghana, Mali and Cote d' Ivoire [23] extending through northern African countries (Egypt and 
Table-1: Real-time Ct values for positive FMDV outbreak epithelial samples

\begin{tabular}{lcllcccc}
\hline Sample ID & Date of outbreak & Location & Protocol & *FAM Ct & FAM Std/ Res & TEST Std/ Res & TEST Ct \\
\hline 1 & $117 / 1 / 2011$ & Bukaru-Rontuwa & FMD & 18.79 & $+\mathrm{Ve}$ & $-\mathrm{Ve}$ & 0.00 \\
2 & $14 / 3 / 2011$ & Bukaru-Rontuwa & FMD & 40.00 & $-\mathrm{Ve}$ & $-\mathrm{Ve}$ & 0.00 \\
3 & $119 / 3 / 2011$ & Bukaru-Rontuwa & FMD & 15.28 & $+\mathrm{Ve}$ & $-\mathrm{Ve}$ & 0.00 \\
\hline
\end{tabular}

* Ct corresponds to the number of cycles required for a given sample to reach the threshold above which it is considered positive. A sample was considered positive when the Ct value was lower than 40, ^Repeated outbreak. FMDV=Foot and mouth disease virus, FAM=6-carboxyfluorescein TEST=6-Tetra chlorofluorescein $\mathrm{Ct}=\mathrm{Cycle}$ threshold

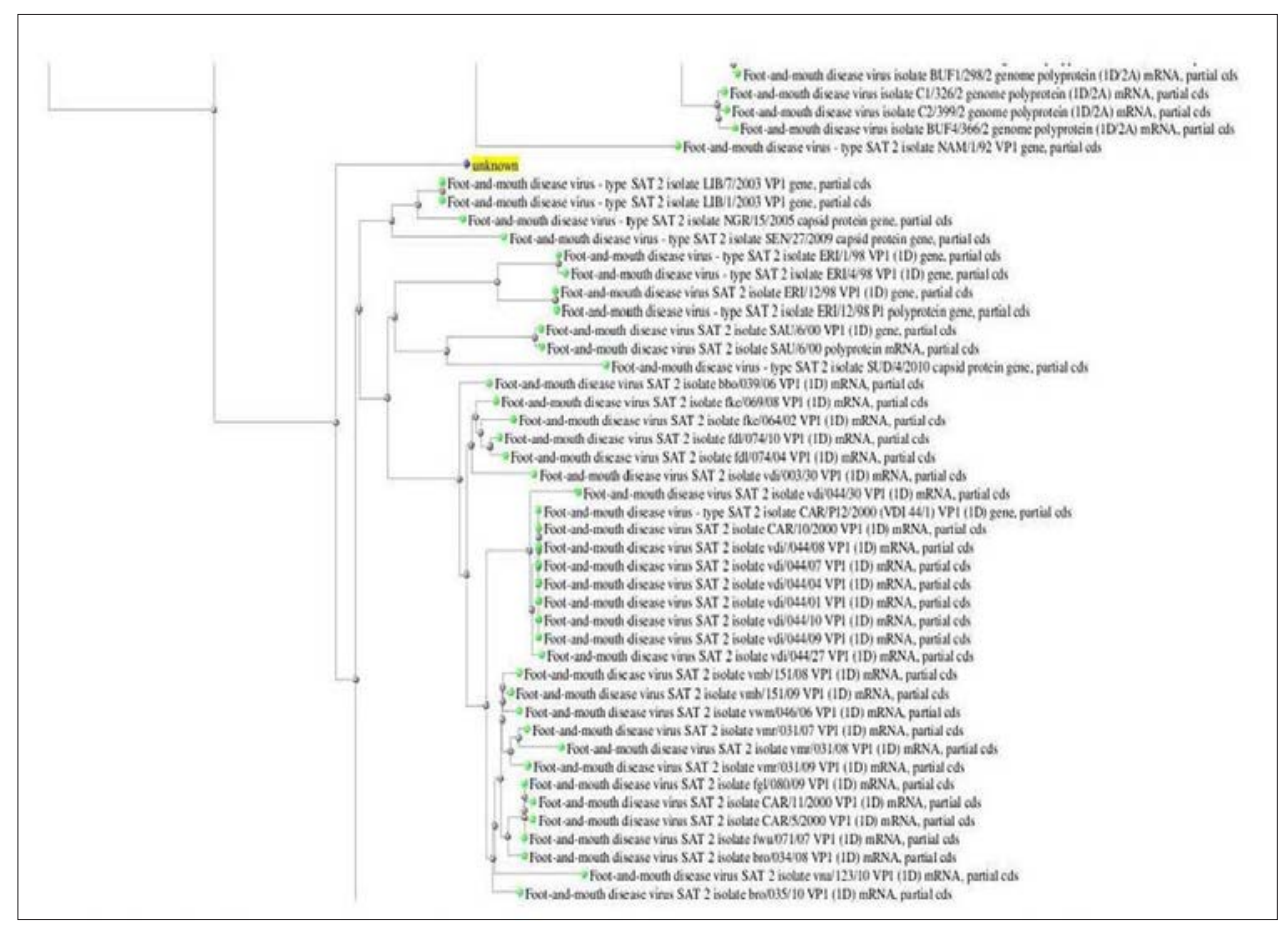

Figure-3: Phylogenic tree view (subset) of Nigerian SAT-2 in this study as compared with sequences from the NCBI database.

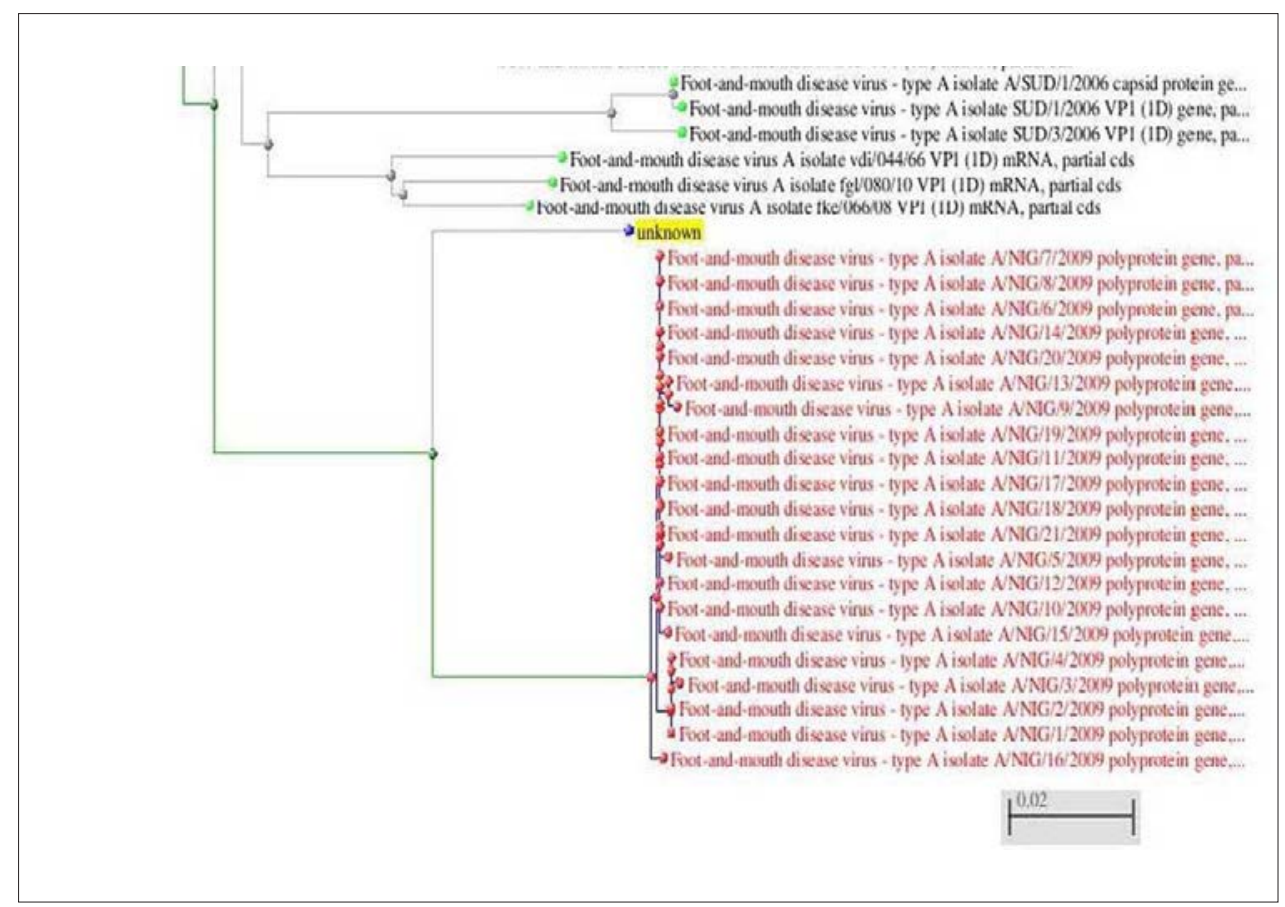

Figure-4: Phylogenic tree view (subset) of Nigerian Serotype A in this study as compared with sequences from the NCBI database.

Libya) into Palestine [22], while serotype A is widespread in Mauritania, Mali, Cote d' Ivoire, Ghana, Niger, Cameroon, Chad and Senegal [24] which are
Nigerian cattle trade partners and potential source of serotype infection. However, nucleotide sequencing further confirmed SAT 2 in this outbreak as closely 


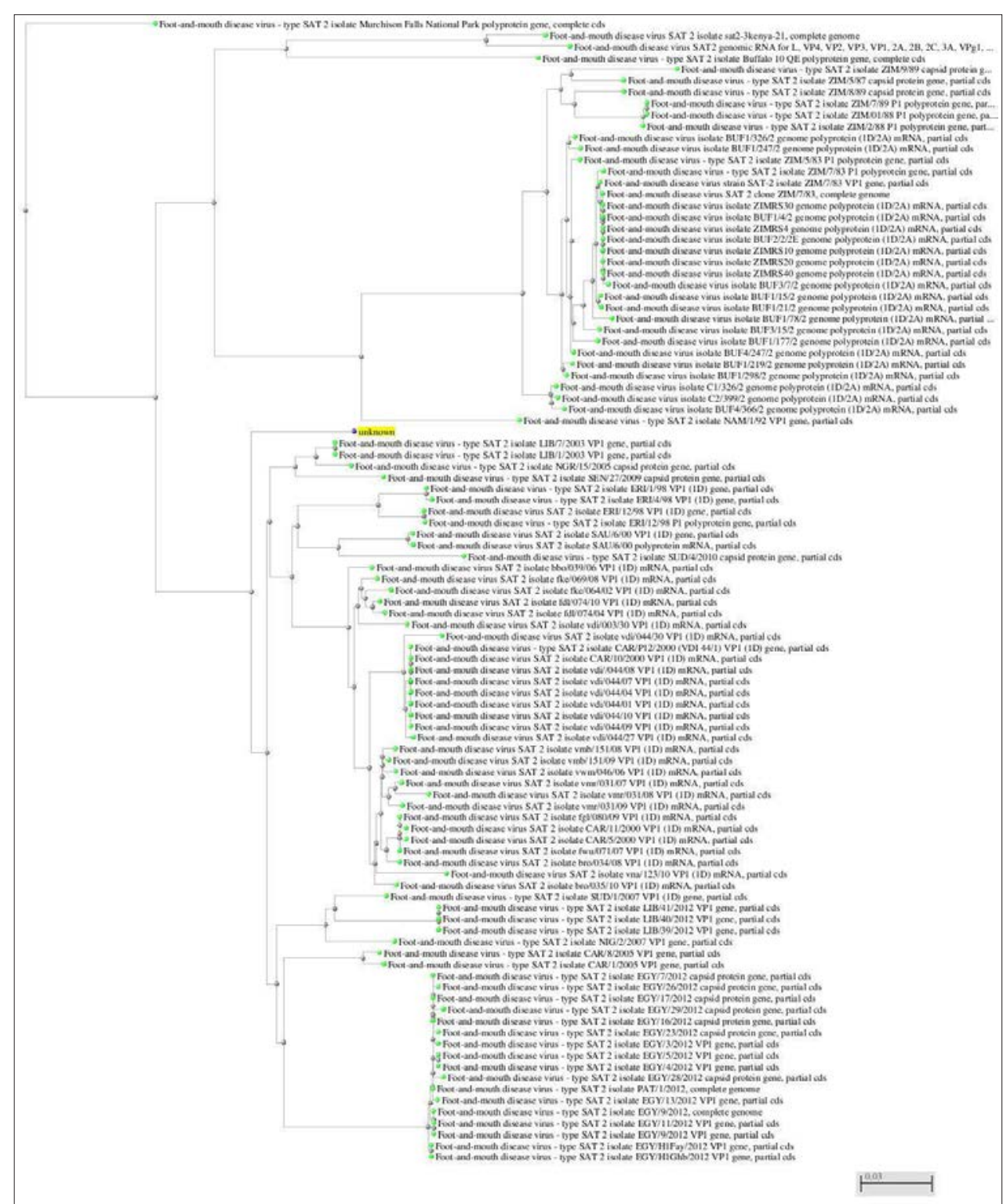

Figure-5: Phylogenic tree view of Nigerian Serotype SAT2 in this study as compared with sequences from the NCBI database.

related with that responsible for previous FMD outbreaks in both Libya and Egypt [25]. This evidence further substantiates for the link between livestock movements and FMD spread from West African countries to North Africa and vice versa.

Furthermore, in this study, cattle were more significant in the maintenance of FMDV, as recovered cattle were not often removed from the herds. Thus, subclinical infections may constitute important viral reservoir precipitating carrier role associated with increasing outbreak occurrence in herds [26]. Also co-habitation scenario of sheep and goats with cattle was observed amongst the Fulani herd settlements studied as these potential small ruminant could act as virus carriers for up to 6 and 9 months [27], militating against effective disease control. However, the observed limited serotype analyzed by PCR and sequencing could be linked to the sample size and status submitted for the procedures as a result of delayed and under reporting of outbreaks, in sufficient logistics and absence of visible epithelial tissues.

\section{Conclusion}

These finding indicates two FMDV serotypes A and SAT 2 similar to A/NIG/21/2009 and SAT 2/LIB/7/2003 isolates as well as other existing circulating Nigerian Type A sequences as etiology of observed outbreaks following circulation of these serotypes amongst susceptible cattle. Therefore, early detection of new FMD serotype outbreaks for disease control using a combination of molecular diagnostic assays is essential especially in border towns like this study area where uncontrolled cattle movement occurs. In addition, samples from FMD carriers and subclinical infections which always threaten susceptible herds could be tested by this method.

Hence, holistic design and implementation of disease control and prevention programmes that 


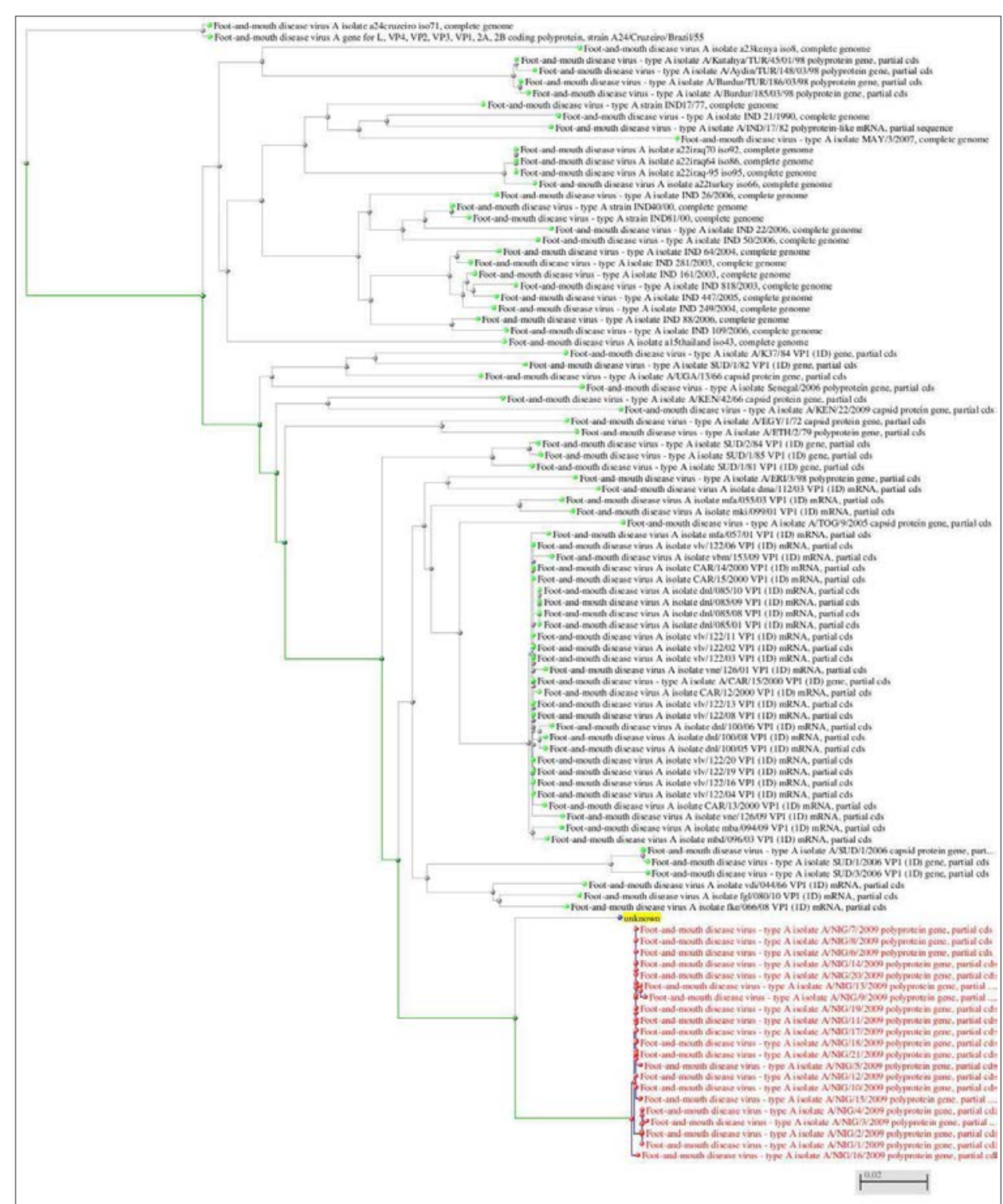

Figure-6: Phylogenic tree view of Nigerian Serotype A in this study as compared with sequences from the NCBI database.

would cub re-occurring outbreaks and spread based on identified serotypes is thus suggested.

\section{Authors Contributions}

This research work is a part of doctorate study of OHO. HMK, and MAR helped in designing, planning and organization of the investigation. They also assisted during result interpretation, discussion and manuscript review. All authors read and approved the final manuscript.

\section{Acknowledgments}

Authors wish to appreciate Dr. Ularamu, H.G, of National Veterinary Research Institute, Vom for enhancing the connection between Dr. Olabode, HOK and Prof. Alexandersen, Soren, (Director), as well as Dr. Zhidong Zhang, of National Centre for Animal Disease, Canadian Food Inspection Agency in Winnipeg, Manitoba, Canada for their contributions in the laboratory analysis of the samples. Personal funds provided by OHO was used for this research work.

\section{Competing I nterest}

All authors gave their informed consent prior to their inclusion in the study as we again declare no conflict and competing interests.

\section{References}

1. Shao, H., Hui-Yun, C., Guang-Qing, Z., Guo-Zheng, C., Jun-Zheng, D., Tong, L., Shan-Dian, G., Ji-Jun, H., XiangTao, L., Ji-Xing, L., and Jin-Liang, G. (2010) RT rapid detection of foot-and-mouth disease virus by reverse transcription loop-mediated isothermal amplification (RT-LAMP). J. Appl. Res. Vet. Med., 8(2): 133-140.

2. Jamal, S.M. and Belsham, G.J. (2013) Foot-and-mouth disease: Past, present and future. Vet. Res., 44: 116-130.

3. Longjam, N., and Tayo, T. (2011) Antigenic variation of foot and mouth disease virus-An overview. Vet. World., 4(10): 475-479.

4. Xue, M., Wang, H., Li, W., Zhou, G., Tu, Y., and Yu, L. (2012) Effects of amino acid substitutions in the VP2 B-C loop on antigenicity and pathogenicity of serotype Asia1 foot and- mouth disease virus. Virol. J., 9: 191-201.

5. Rweyemamu, M., Roeder, P., Mackay, D., Sumption, K., Brownlie, J., Leforban, Y., Valarcher, J.F., Knowles, N.J. and 
Saraiva, V. (2008) Epidemiological patterns of foot-and-mouth disease worldwide. Transbound. Emerg. Dis., 55: 57-72.

6. Depa, P.M., Dimri, U., Sharma, M.C. and Tiwari, R. (2012) Update on epidemiology and control of foot and mouth disease - A menace to international trade and global animal enterprise. Vet. World., 5(11): 694-704.

7. Lazarus, D.D., Schielen, W.J.G., Wungak, Y., Kwange, D., and Fasina, F.O. (2012) Sero-epidemiology of foot-andmouth disease in some border states of Nigeria. Afr. $J$. Microbiol. Res., 6(8): 1756-1761.

8. Olabode, H.O.K. (2012) Foot and mouth disease in Nigeria: The current status and control efforts. A Paper presented at the global foot and mouth disease research alliance workshop organized by ARC-Onderstepoort Veterinary Institute, held at Hazy-view, Kurger National Park, South Africa on the $17^{\text {th }}-19^{\text {th }}$ April, 2012. Available from: http://www.ars.usda. gov/GFRA/presentations/Session3/3.4OlabodeFMD\%20 powerpoint.pdf.

9. Van Phan, L., Kwang-Nyeong, L., Tung, N., Su-Mi, K., In-Soo, C, Dinh, D.K, Nguyen, B.H., Dong, V.Q. and JongHyeon, P. (2012) A rapid molecular strategy for early detection and characterization of foot and mouth disease virus serotypes A, O and Asia 1. J. Virol. Meth., 180(1-2): 1-6.

10. Tian, H., Wu, J., Shang, Y., Cheng, Y., and Liu, X.T. (2010) The development of a rapid SYBR one step real-time RT-PCR for detection of porcine reproductive and respiratory syndrome virus. Virol. J., 7: 90-97.

11. El-Shehawy, L., Azab, A.M.H., Mossad, W., El-Sayed, E., Ismail, A., and Deghady, W. (2012) Real time RT-PCR assay for detection of different serotypes of FMDV in Egypt. Vet. World., 5(12): 732-737.

12. Megersa, B., Beyene, B., Abunna, F., Regassa, A., Amenu, K., and Rufael, T. (2009) Risk factors for foot and mouth disease seroprevalence in indigenous cattle in southern Ethiopia: The effect of production system. Trop. Anim. Health Prod., 41(6): 891-8.

13. Olabode, H.O.K., Kazeem, H.M., Raji, M.A. and Ibrahim, N.D.G. (2014) Participatory appraisal of foot and mouth disease outbreaks in Ilesha Baruba, Kwara state-Nigeria. Alex. J. Vet. Sci. AJVS., 40: 132-138.

14. Anonymous (2011) Baruteen Local Government Area of Kwara State. Available from: http://www.kwarastate.gov. ng/baruteen-local-government-area.html. [Last accessed on 2011 Jul 20].

15. Office International for Epizootics (OIE). (2012) Foot and mouth disease. In: OIE Terrestrial Manual. Ch. 2.1.5. http:// www.oie.int/en/our-scientific-expertise/reference-laboratories/list-of-laboratories/) p1-29. Last accessed on 28-08-2014.
16. Knowles, N.J. and Samuel, A.R. (1998) RT-PCR and sequencing protocols for the molecular epidemiology of exotic virus diseases of animals - OIE/FAO-WRL-FMD: Molecular Epidemiology Group. p5-20.

17. Moniwa, M., Clavijo, A., Li, M., Collignon, B., and Kitching, R.P. (2007) Performance of a foot-and-mouth disease virus reverse transcription-polymerase chain reaction with amplification controls between three real-time instruments. J. Vet. Diagn. Invest., 19(1): 9-20.

18. Page, R.D.M. (1996) TREEVIEW: An application to display phylogenetic trees on personal computers. Comput. Appl. Biosci., 12(4): 357-358.

19. Durojaiye, A.O. (1981) Incidence of foot and mouth disease in Oyo state of Nigeria. Niger Vet. J., 10: 7-13.

20. Nagendrakumar, S.B., Madhanmohan, M., Rangarajan, P.N. and Srinivasan, V.A. (2009) Genetic analysis of foot-and-mouth disease virus serotype A of Indian origin and detection of positive selection and recombination in leader protease- and capsid-coding regions. $J$. Biosci., 34(1): 85-101.

21. Di Nardo, A., Knowles, N.J. and Paton, D.J. (2011) Combining livestock trade patterns with phylogenetics to help understand the spread of foot and mouth disease in sub-Saharan Africa, the Middle East and Southeast Asia. Sci. Tech. Rev. Off. Int. Epiz., 30(1): 63-85.

22. Valdazo-González, B., Knowles, N.J., Hammond, J., and King, D.P. (2012) Genome sequences of SAT 2 foot-andmouth disease viruses from Egypt and Palestinian autonomous territories (Gaza Strip). J. Virol., 86(16): 8901-8902.

23. Bastos, A.D.S., Haydon, D.T., Sangare, O., Boshoff, C.I., Edrich, J.L. and Thomson, G.R. (2003) The implications of virus diversity within the SAT 2 serotype for control of footand-mouth disease in sub-Saharan Africa. J. Gen. Virol., 84(6): 1595-1606.

24. Vosloo, W., Bastos, A.D.S., Sangare, O., Hargreaves, S.K. and Thomson, G.R. (2002) Review of the status and control of foot and mouth disease in Sub-Saharan Africa. Sci. Tech. Rev. Off. Int. Epiz., 21(3): 437-449.

25. Food and Agriculture Organization of the United Nations (FAO). (2012) Foot-and-Mouth disease caused by serotype SAT2 in Egypt and Libya: A regional concern for animal health in North Africa and the Middle East. EMPRES WATCH, Vol. 25, March 2012. Rome.

26. Arzt, J., Juleff, N., Zhang, Z., and Rodriguez, L.L. (2011) The pathogenesis of foot-and-mouth disease I: Viral pathways in cattle. Transbound. Emerg. Dis., 58: 291-304.

27. Kitching, R.P. and Hughes, G.J. (2002) Clinical variation in foot and mouth disease: Sheep and goats. Sci. Tech. Rev., 21(3): 505-512. 